\title{
Beyond the Concept of Winter-Summer Leaves of Mediterranean Seasonal Dimorphic Species
}

\author{
Giacomo Puglielli* \\ Chair of Biodiversity and Nature Tourism, Estonian University of Life Sciences, Tartu, Estonia
}

Keywords: leaf cohorts, intraindividual variability, trait-environment relationships, climate change, seasonality

\section{INTRODUCTION}

OPEN ACCESS

Edited by:

Erik T. Nilsen,

Virginia Tech, United States

Reviewed by:

Philip Rundel,

University of California, Los Angeles,

United States

Constantinos Nikiforou,

European University Cyprus, Cyprus

Sara Palacio,

Spanish National Research Council

(CS/C), Spain

*Correspondence:

Giacomo Puglielli

giacomo.puglielli@gmail.com

Specialty section:

This article was submitted to

Functional Plant Ecology,

a section of the journal

Frontiers in Plant Science

Received: 08 February 2019

Accepted: 09 May 2019

Published: 31 May 2019

Citation:

Puglielli G (2019) Beyond the Concept

of Winter-Summer Leaves of

Mediterranean Seasonal Dimorphic

Species. Front. Plant Sci. 10:696.

doi: 10.3389/fp/s.2019.00696
One of the dominant growth forms in Mediterranean ecosystems is represented by seasonally dimorphic (semi-deciduous) species. Seasonal dimorphism has been long considered as a key adaptation to the seasonality of the Mediterranean type of climate for shrub species inhabiting the Mediterranean Basin (batha, phrygana and maquis shrublands, Orshan, 1964; Margaris, 1975, 1977; Margaris et al., 1984; Christodoulakis et al., 1990; Gratani and Crescente, 1997; Kyparissis et al., 1997; Díaz Barradas et al., 1999), Californian chaparral (Westman, 1981; Mooney and Miller, 1985), Chilean matorral (Montenegro et al., 1979) and South African Cape karroid shrublands (Westman, 1981). The main feature of seasonal dimorphic species is the development of two well-defined leaf cohorts during a growing season, the so-called "winter" and "summer" leaves (Westman, 1981, Nilsen et al., 1986; Aronne and De Micco, 2001), hereafter referred as WL and SL, respectively.

Nevertheless, there is evidence that seasonal dimorphism can be flexible (Orshan and Zand, 1962; Orshan, 1964; Westman, 1981; Kyparissis et al., 1997; Palacio et al., 2006, 2008; Puglielli et al., 2017, in press; Puglielli and Varone, 2018), so that the extent of differences between WL and SL, as well as the number of cohorts during a growing season, depend on species and environmental conditions at a given site. For instance, the existence of an intermediate step between WL and SL (generally called spring leaves) has been suggested in previous studies on seasonal dimorphic species (e.g., Palacio et al., 2006; de Dato et al., 2013; Puglielli et al., in press). At any rate, the flexibility of seasonal dimorphism can result in leaves to be formed under different prevailing environmental conditions due to the seasonality of the Mediterranean climate and significant changes in leaf traits are expected between leaves formed in different periods during a given growing season (Morales et al., 2014; Niinemets, 2014). The presence of multiple leaf cohorts during a growing season should be reflected by a great degree of intraindividual variability in leaf traits, but this has never been analyzed in an explicit way.

\section{INTRAINDIVIDUAL VARIABILITY IN SEASONAL DIMORPHIC SPECIES: DIFFERENCES BETWEEN AND WITHIN LEAF COHORTS}

Seasonal dimorphic species indeed display a high variability of several functional traits during one growing season. By calculating coefficient of variations (CV) for leaf length, width, area (LA), leaf 
mass area (LMA), thickness and nitrogen content on area basis for four Cistus spp. from Correia and Ascensão (2017), average trait variability spans from 25 to $51 \%$ during an entire growing season depending on the species. Similarly, Palacio et al. (2008) by analyzing seasonal changes in leaf dry matter content (LDMC) in four Mediterranean seasonal dimorphic species, found a 2- to 3-fold variation at the intraspecific level and such seasonal changes were higher than interspecific differences. They also found that different cohorts were simultaneously present in different types of shoots occupying different positions along the heteroblastic series, stressing the relationship between leaf trait variability and the presence of multiple cohorts.

Comparable trends over a season can be also observed for the Mediterranean seasonal dimorphic Halimium halimifolium growing in four sites differing in water availability (Díaz Barradas et al., 1999). Calculating CVs for LA, leaf dry mass (DM) and LMA, CVs range between 103-143\% for LA, $25-30 \%$ for DM, and $6-28 \%$ for LMA, in line with the previous data on Cistus spp. However, it is interesting to point out that LMA variability in Díaz Barradas et al. (1999) depends on site. If we consider LMA as an indicator of shifts in leaf level strategies between leaf cohorts, such dependence of leaf traits variability on the site reflects the possible convergence/divergence between leaf cohorts as affected by environmental conditions (see previous section and Palacio et al., 2006).

Recently, it has been also demonstrated (Puglielli and Varone, 2018) that there is a great inherent variability of leaf functional traits in WL and SL of 9 Cistus spp. (43\% of the species belonging to the genus) across the Mediterranean Basin. Also, the authors found that the considered traits had overlapped ranges of trait variation between leaf cohorts (Figure 1). This confirms that leaves belonging to different leaf cohorts can converge in some circumstances in terms of mean values of leaf traits as a result of the high degree of variability of climatic factors within the Mediterranean Basin.

Surprisingly, a similar magnitude of traits variation can be found even in the medium-term (i.e., few months) within WL and SL in Cistus spp. (Correia and Ascensão, 2017) for key leaf traits, such as leaf area (LA) and leaf mass area (LMA). For two Cistus spp. for example, CV for LA is, on average, 69 and $63 \%$ for WL and SL, while those for LMA are 30 and $5 \%$ compared to those calculated over a growing season of $71 \%$ for LA and $33 \%$ for LMA. Similarly, a degree of variability for LA up to 40 and $60 \%$ can be found within WL and SL belonging to the same plant in five seasonal dimorphic species of Californian coastal sage in Westman (1981), with average coefficient of variations across species of 20 and $42 \%$ for $\mathrm{WL}$ and SL, respectively. Such great variability results in a 3- to 21-fold difference in LA between WL and SL, underscoring that intraindividual differences between these leaf cohorts can be more or less pronounced even at the level of a single plant.

At the within leaf cohort level, Puglielli et al. (2017) demonstrated that WL (sampled between November and

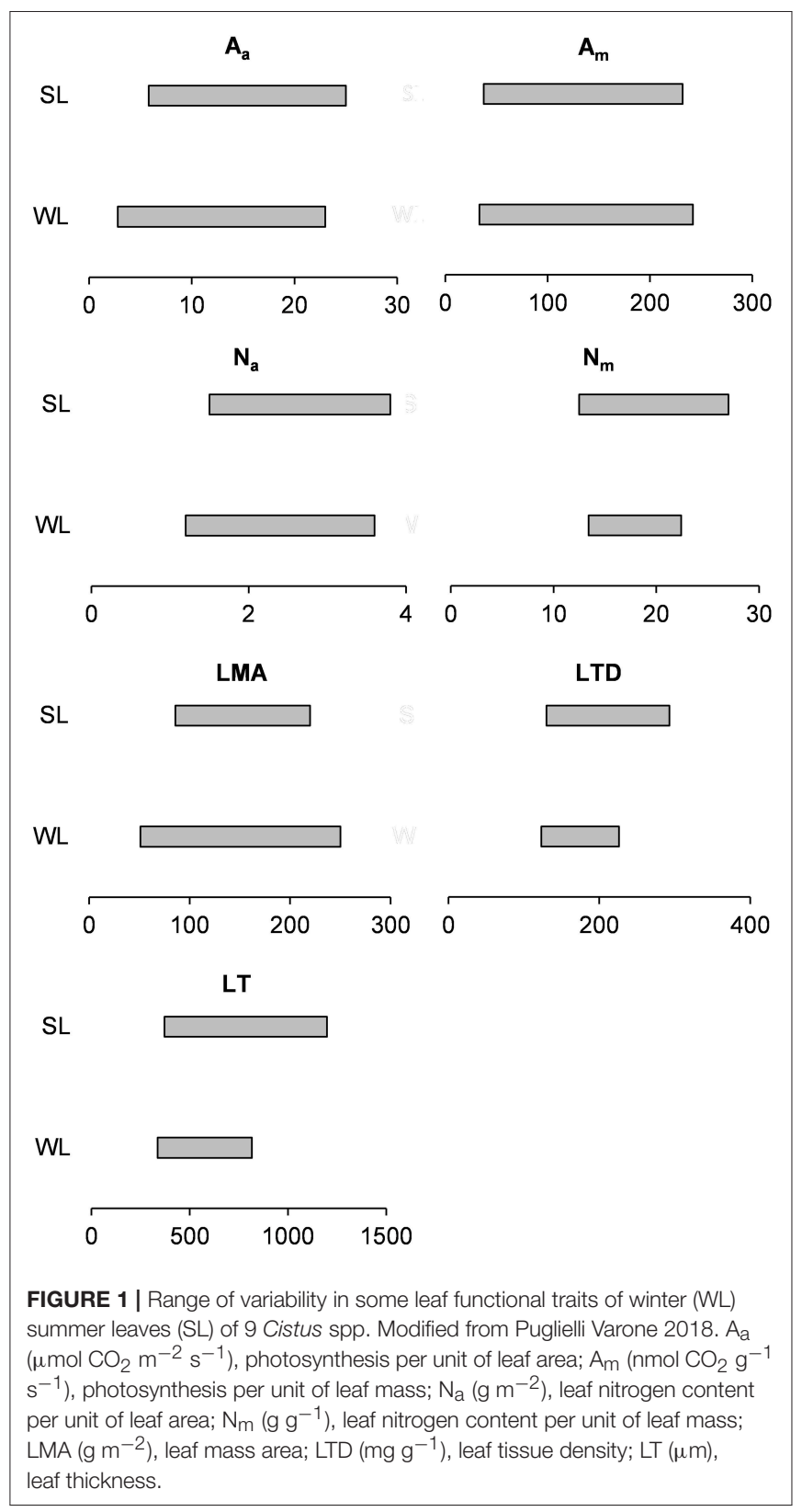

April) of three Cistus spp. have different slopes for the relationship LMA-photosynthesis per unit of leaf mass $\left(A_{m}\right)$ during the transition from winter to spring. This result is particularly relevant since $A_{m}$ characterizes the biochemical capacity of single cells and is the key player in the worldwide trade-off between the physiological and structural characteristics of leaves (Westoby et al., 2013; Niinemets et al., 2015; Tosens et al., 2016). So, changes of bivariate relationships LMA- $A_{m}$ indeed highlight leaf specific adaptations to particular environmental conditions (Wright et al., 2004). Significant differences in slopes of bivariate relationships between functional traits with varying environmental conditions have been further 
confirmed during an entire growing season (from November to July, Puglielli et al., in press).

\section{FUNCTIONAL ROLE OF INTRAINDIVIDUAL VARIABILITY IN SEASONAL DIMORPHIC SPECIES: INSIGHTS FROM CISTUS SPP.}

Overall, the previous analysis supports the existence of a seasonal spectrum of leaf traits variation which can be unlikely represented by a simple "winter-summer" classification of seasonal dimorphic species leaf cohorts. In other words, the degree of intraindividual variability in leaf traits of seasonal dimorphic species can be underestimated by analyzing only differences between leaf cohorts that mostly picture broad differences between leaves formed at the extremes of a given growing season. Accordingly, more detailed leaf flushing analyses on seasonal dimorphic species have already revealed contrasting patterns across species in different climatic conditions which were not always consistent with seasonal dimorphism itself (Palacio et al., 2006).

At any rate, the functional role of intrandividual variability in seasonal dimorphic species along a growing season has not yet been clarified. Analysis of the changes in leaf traits covariation patterns between leaf cohorts of Cistus spp. (see Puglielli and Varone, 2018; Puglielli et al., in press) can provide some insights on the functional relevance of such variability. A different acclimation of leaves to different environmental conditions, as expected for different leaf cohorts, should be highlighted by consistent differences in slopes and/or intercepts of bivariate relationships between leaf functional traits (i.e., "Shift 2 scenario" sensu Wright et al., 2001). Nevertheless, this was not always the case for a broad comparison of WL vs. SL (Puglielli and Varone, 2018), nor for leaves diachronically formed along a given growing season (Puglielli et al., in press). Interestingly, seasonal changes in slopes of the bivariate relationships can parallel changes in resourceacquisition and use strategies sensu (Pierce et al., 2013; Puglielli et al., in press), partially providing a mechanistic explanation of a seasonal spectrum of traits variation. So, Cistus spp., and likely other seasonal dimorphic species, can shift from a relatively lower (more stress tolerant) to a relatively higher (more competitive) return strategy in the mediumterm by adjusting trade-off rates between functional traits to the prevailing environmental conditions in which the leaves are formed. Such behavior also stresses a previous hypothesis from Niinemets (2014, but see also Puglielli and Varone, 2018) that leaf flushing strategy (i.e., the number of leaf cohorts) may be an important driver altering the leaf economic spectrum (Wright et al., 2004).

Herrera et al. (2015), but see also Herrera (2009), argued that interpreting the adaptive role of within-plant variation in functional traits requires an independence between intraindividual variability in a given trait and trait means. In a similar fashion, this is what Puglielli et al. (in press) somewhat found: the above mentioned slopes of bivariate relationships followed seasonal changes of the climatic factors according to temperature response curves while mean values did not.

Thus, the degree of intraindividual variability in leaf traits along a growing season is linked to seasonal dimorphic species ability to adjust in the medium-term leaf physiology and morphology (and their relationships) to changing environmental conditions. This is particularly important in view of the unpredictability of the Mediterranean climate, since such fine adjustments can enable seasonal dimorphic species to efficiently track favorable (and mostly variable) climatic conditions in order to maximize whole-plant performance. In line with this statement, intraindividual variation in functional leaf traits has been proposed to be a means to optimize exploitation of environmental variation both in time and space and to enhance wholeplant photosynthetic performance (Givnish, 1988; Mulkey et al., 1992; Hollinger, 1996; Winn, 1996, 1999; Osada et al., 2014; Herrera et al., 2015).

Nevertheless, one can argue that intraindividual modifications in both leaf structure and function as well as their relationships along a growing season can be a costly strategy in species characterized by a relatively short leaf life span, such as seasonal dimorphic species. However, leaves formed under different environmental conditions can mostly coexist in the canopy until the onset of summer drought. So, I argue that changes in leaf traits trade-off rates over an entire growing season can balance the rate of return of the investment made in leaf stiffness and/or carbon gain in the long term. This would make species able to maintain the costs of leaf economics' even if the single leaves are characterized by a relatively short leaf life span.

\section{CONCLUDING REMARKS}

A great degree of intraindividual variability in seasonal dimorphic species and its link with environmental changes undermine the efficacy of a simple "winter-summer" leaf classification. In fact, when accounting for this source of variability, which magnitude can be comparable to interspecific one (Iannetta et al., 2007; Boucher et al., 2013; Laforest-Lapointe et al., 2014; Medrano et al., 2014; Mitchell and Bakker, 2014; Herrera et al., 2015), differences between WL and SL can be less marked or even disappear.

At any rate, the degree of intraindividual variability depends on the number of leaf flushes during one growing season, which in turn is strongly affected by climate (Niinemets, 2014). These considerations become extremely important in a context of climatic changes which are not only expected to modify the length of the favorable period for growth of Mediterranean species (Correia and Ascensão, 2017), but also to generate stochastic changes of the thermal amplitudes over the year, with predictable consequences on leaf structuring and functioning. 
Most of research involving seasonal dimorphic species has been focused on the differences between WL and SL. However, a shift in focus on the continuous effect of seasonal environmental changes on intraindividual variability of leaf traits in seasonal dimorphic species is strongly needed to provide new mechanistic insights on how these species thrive in the ever-changing climatic conditions typical of the Mediterranean climate.

\section{AUTHOR CONTRIBUTIONS}

The author confirms being the sole contributor of this work and has approved it for publication.

\section{REFERENCES}

Aronne, G., and De Micco, V. (2001). Seasonal dimorphism in the Mediterranean Cistus incanus L. subsp. incanus. Ann. Bot. 87, 789-794. doi: 10.1006/anbo.2001.1407

Boucher, F. C., Thuiller, W., Arnoldi, C., Albert, C. H., and Lavergne, S. (2013). Unravelling the architecture of functional variability in wild populations of Polygonum viviparum L. Funct. Ecol. 27, 382-391. doi: 10.1111/1365-2435.12034

Christodoulakis, N. S., Tsimbani, H., and Fasseas, C. (1990). Leaf structural peculiarities in Sarcopoterium spinosum, a seasonally dimorphic subshrub. Ann. Bot. 65, 291-296. doi: 10.1093/oxfordjournals.aob.a087937

Correia, O., and Ascensão, L. (2017). "Summer semi-deciduous species of the Mediterranean landscape: a winning strategy of Cistus species to face the predicted changes of the Mediterranean climate", in Plant Biodiversity: Monitoring, Assessment and Conservation, eds A. Ansari, S. S. Gill, and M. Naeem (Oxford: CABI), 195-217. doi: 10.1079/9781780646947.0195

de Dato, G. D., Micali, M., Jaoudéc, R. A., Liberati, D., and De Angelis, P. (2013). Earlier summer drought affects leaf functioning of the Mediterranean species Cistus monspeliensis L. Environ. Exp. Bot. 93, 13-19. doi: 10.1016/j.envexpbot.2013.03.007

Díaz Barradas, M. C., Zunzunegui, M., and García Novo, F. (1999). Autecological traits of Halimium halimifolium in contrasting habitats under a Mediterranean type climate-a review. Folia Geob. 34, 189-208. doi: 10.1007/BF02913395

Givnish, T. J. (1988). Adaptation to sun and shade: a whole-plant perspective. Austr. J. Plant Physiol. 15, 63-92. doi: 10.1071/PP9880063

Gratani, L., and Crescente, M. F. (1997). Phenology and leaf adaptive strategies of Mediterranean maquis plants. Ecol. Mediterr. 23, 11-19.

Herrera, C. M. (2009). Multiplicity in Unity. Plant Subindividual Variation and Interactions With Animals. Chicago, IL: University of Chicago Press.

Herrera, C. M., Medrano, M., and Bazaga, P. (2015). Continuous within-plant variation as a source of intraspecific functional diversity: patterns, magnitude, and genetic correlates of leaf variability in Helleborus foetidus (Ranunculaceae). Am. J. Bot. 102, 225-232. doi: 10.3732/ajb.1400437

Hollinger, D. Y. (1996). Optimality and nitrogen allocation in a tree canopy. Tree Physiol. 16, 627-634. doi: 10.1093/treephys/16.7.627

Iannetta, P. P. M., Begg, G., Hawes, C., Young, M., Russell, J., and Squire, G. R. (2007). Variation in Capsella (shepherd's purse): an example of intraspecific functional diversity. Physiol. Plantarum 129, 542-554. doi: 10.1111/j.1399-3054.2006.00833.X

Kyparissis, A., Grammatikopoulos, G., and Manetas, Y. (1997). Leaf demography and photosynthesis as affected by the environment in the drought semideciduous Mediterranean shrub Phlomis fruticosa L. Acta Oecol. 18, 543-555. doi: 10.1016/S1146-609X(97)80040-9

Laforest-Lapointe, I., Martínez-Vilalta, J., and Retana, J. (2014). Intraspecific variability in functional traits matters: case study of Scots pine. Oecologia 175, 1337-1348. doi: 10.1007/s00442-014-2967-x

\section{FUNDING}

GP research is supported by the European Regional Development Fund and the program Mobilitas Pluss (Grant No MOBJD350). This study was also supported by the Estonian Research Council (Grant No PUT 1409).

\section{ACKNOWLEDGMENTS}

I want to thank Dr. Laura Varone for her support and patience while I was developing these ideas during my Ph.D. research and the reviewers for their insightful comments. I am also grateful to Prof. Marí Cruz Díaz Barradas for her comments on a previous version of the manuscript and for motivating me to keep writing.

Margaris, N. S. (1975). Effect of photoperiod on seasonal dimorphism of some mediterranean plants. Ber. Schweiz. Bot. Ges. 85, 96-102.

Margaris, N. S. (1977). Physiological and biochemical observations in seasonal dimorphic leaves of Sarcopoterium spinosurn and Phlomis fruticosa. Oecol. Plant. 12, 343-350.

Margaris, N. S., Adamandiadou, S., Siafaca, L., and Diamantopoulos, J. (1984). Nitrogen and phosphorus content in plant species of Mediterranean ecosystems in Greece. Vegetatio 55, 29-35. doi: 10.1007/BF00039978

Medrano, M., Herrera, C. M., and Bazaga, P. (2014). Epigenetic variation predicts regional and local intraspecific functional diversity in a perennial herb. Mol. Ecol. 23, 4926-4938. doi: 10.1111/mec.12911

Mitchell, R. M., and Bakker, J. D. (2014). Quantifying and comparing intraspecific functional trait variability: a case study with Hypochaeris radicata. Funct. Ecol. 28, 258-269. doi: 10.1111/1365-2435.12167

Montenegro, G., Aljaro, M. E., and Kummerow, J. (1979). Growth dynamics of Chilean matorral shrubs. Bot. Gaz. 140, 114-119. doi: 10.1086/337065

Mooney, H. A., and Miller, P. C. (1985). "Chaparral", in Physiological Ecology of North American Plant Communities, eds B. F. Chabot, and H. A. Mooney (Dordrecht: Springer), 213-231. doi: 10.1007/978-94-009-4830-3_10

Morales, L. V., Coopman, R. E., Rojas, R., Escandón, A. B., Flexas, J., Galmes, J., et al. (2014). Acclimation of leaf cohorts expanded under light and water stresses: an adaptive mechanism of Eucryphia cordifolia to face changes in climatic conditions? Tree Physiol. 34, 1305-1320. doi: 10.1093/treephys/tpu085

Mulkey, S. S., Smith, A. P., Wright, S. J., Machado, J. L., and Dudley, R. (1992). Contrasting leaf phenotypes control seasonal variation in water loss in a tropical forest shrub. Proc. Natl. Acad. Sci. U.S.A. 89, 9084-9088. doi: 10.1073/pnas.89.19.9084

Niinemets, Ü, Keenan, T. F., and Hallik, L. (2015). A worldwide analysis of withincanopy variations in leaf structural, chemical and physiological traits across plant functional types. New Phytol. 205, 973-993. doi: $10.1111 /$ nph.13096

Niinemets, Ü. (2014). Cohort-specific tuning of foliage physiology to interacting stresses in evergreens. Tree Physiol. 34, 1301-1304. doi: 10.1093/treephys/tpu099

Nilsen, E. T., Sharifi, M. R., Rundel, P. W., and Virginia, R. A. (1986). Influences of microclimatic conditions and water relations on seasonal leaf dimorphism of Prosopis glandulosa var. torreyana in the Sonoran Desert, California. Oecologia 69, 95-100. doi: 10.1007/BF00399043

Orshan, G. (1964). "Seasonal dimorphism of desert and Mediterranean chamaephytes and its significance as a factor in their water economy", in The Water Relations of Plants, eds. A. J. Rutter, and F. H. Whitehead (Edinburgh: Blackwell), 206-222.

Orshan, G., and Zand, G. (1962). Seasonal body reduction of certain desert halfshrubs. Bull. Res. Coun. Isr. 11, 35-42.

Osada, N., Yasumura, Y., and Ishida, A. (2014). Leaf nitrogen distribution in relation to crown architecture in the tall canopy species, Fagus crenata. Oecologia 175, 1093-1106. doi: 10.1007/s00442-014-2966-y 
Palacio, S., Milla, R., Albuixech, J., Pérez-Rontomé, C., Camarero, J. J., Maestro, M., et al. (2008). Seasonal variability of dry matter content and its relationship with shoot growth and nonstructural carbohydrates. New Phytol. 180, 133-142. doi: $10.1111 / j .1469-8137.2008 .02569 . x$

Palacio, S., Millar, P., and Montserrat-Martí, G. (2006). Aboveground biomass allocation patterns within Mediterranean sub-shrubs: a quantitative analysis of seasonal dimorphism. Flora 201, 612-622. doi: 10.1016/j.flora.2006.02.002

Pierce, S., Brusa, G., Vagge, I., and Cerabolini, B. E. L. (2013). Allocating CSR plant functional types: the use of leaf economics and size traits to classify woody and herbaceous vascular plants. Funct. Ecol. 27, 1002-1010. doi: 10.1111/1365-2435.12095

Puglielli, G., Cuevas Román, F. J., Catoni, R., Moreno Rojas, J. M., Gratani, L., and Varone, L. (2017). Provenance effect on carbon assimilation, photochemistry and leaf morphology in Mediterranean Cistus species under chilling stress. Plant Biol. 19, 660-670. doi: 10.1111/plb.12574

Puglielli, G., and Varone, L. (2018). Inherent variation of functional traits in winter and summer leaves of Mediterranean seasonal dimorphic species: evidence of a 'within leaf cohort' spectrum. AoB Plants 10: ply027. doi: 10.1093/aobpla/ply027

Puglielli, G., Varone, L., and Gratani, L. (in press). Diachronic adjustments of functional traits scaling relationships to track environmental changes: revisiting Cistus species leaf cohort classification. Flora. doi: 10.1016/j.flora.2018.08.010

Tosens, T., Nishida, K., Gago, J., Coopman, R. E., Cabrera, H. M., Carriqui, M., et al. (2016). The photosynthetic capacity in 35 ferns and fern allies: mesophyll $\mathrm{CO}_{2}$ diffusion as a key trait. New Phytol. 209, 1576-1590. doi: $10.1111 /$ nph.13719

Westman, W. E. (1981). Seasonal dimorphism of foliage in Californian coastal sage scrub. Oecologia 51, 385-388. doi: 10.1007/BF00540910
Westoby, M., Reich, P. B., and Wright, I. J. (2013). Understanding ecological variation across species: area-based vs mass-based expression of leaf traits. New Phytol. 199, 322-323. doi: 10.1111/nph.12345

Winn, A. A. (1996). The contributions of programmed developmental change and phenotypic plasticity to within-individual variation in leaf traits in Dicerandra linearifolia. J. Evol. Biol. 9, 737-752. doi: 10.1046/ j.1420-9101.1996.9060737.x

Winn, A. A. (1999). Is seasonal variation in leaf traits adaptive for the annual plant Dicerandra linearifolia? J. Evol. Biol. 12, 306-313. doi: 10.1046/j.1420-9101.1999.00031.x

Wright, I. J., Reich, P. B., and Westoby, M. (2001). Strategy shifts in leaf physiology, structure and nutrient content between species of high- and low-rainfall and high and low-nutrient habitats. Funct. Ecol. 15, 423-434. doi: 10.1046/j.0269-8463.2001.00542.x

Wright, I. J., Reich, P. B., Westoby, M., Ackerly, D. D., Baruch, Z., Bongers, F., et al. (2004). The world-wide leaf economics spectrum. Nature 428, 821-827. doi: 10.1038 /nature02403

Conflict of Interest Statement: The author declares that the research was conducted in the absence of any commercial or financial relationships that could be construed as a potential conflict of interest.

Copyright $\odot 2019$ Puglielli. This is an open-access article distributed under the terms of the Creative Commons Attribution License (CC BY). The use, distribution or reproduction in other forums is permitted, provided the original author(s) and the copyright owner(s) are credited and that the original publication in this journal is cited, in accordance with accepted academic practice. No use, distribution or reproduction is permitted which does not comply with these terms. 